\title{
भारतीय संस्कृति में वर्तमान पर्यावरणीय समस्याओं का स्थायी समाधान
}

मनोज कुमार राव

सारांश

इक्कीसवीं सदी विज्ञान एवं तकनीकी का युग है। इस विज्ञान एवं तकनीकी के माध्यम से वर्तमान युग में भौतिक समृद्धि एवं साधनों की अपार वृद्धि हुई है। प्राकृतिक संसाधनों के माध्यम से व्यापक स्तर पर भौतिक जीवन के साधनों का निर्माण हो रहा है। प्राकृतिक संसाधनों के असीमित दोहन के कारण जहाँ एक तरफ पारिस्थितिकीय असंतुलन उत्पन्न हो रहा है वहीं दूसरी तरफ उद्योगों एवं विविध प्रकार के मानव निर्मित भौतिक साधनों से उत्सर्जित हानिकारक तत्वों से पर्यावरण प्रदूषण बड़ी तेजी से बढ़ रहा है, जिसके फलस्वरूप आये दिन लोगों को सर्वनाशी समस्याओं का सामना करना पड़ रहा है। आज जहाँ जीवन को सुखमय और खुशहाल बनाने की चाह है वहीं अपने अस्तित्व को खो देने का भय भी है। मानवीय अस्तित्व की रक्षा के लिए इन समस्याओं का समाधान अति आवश्यक है। इन समस्याओं का स्थायी समाधान एक मात्र भारतीय संस्कृति की प्रकृति विषयक आध्यात्मिक चिंतन में है जिसको अपना कर मनुष्य अपने सुख, समृद्धि एवं अस्तित्व के साथ-साथ पर्यावरण को भी सुरक्षित तथा संरक्षित रख सकता है। प्रस्तुत शा 
भारतीय संस्कृति में पर्यावरणीय समस्याओं का समाधान

'पर्यावरण' शब्द 'परि' और 'आड्.' उपसर्ग पूर्वक वरणार्थक 'वृड् तथा 'वृआा' धातु से 'ल्यूट' प्रत्यय के मिलने 
जड़-चेतन सभी तत्वों में, कण-कण में ईश्वर का वास है (ईशोपनिषद् - 2)। यह जान लेने पर व्यक्ति के हृदय में 'आत्मवत सर्वभूतेषु' का भाव विकसित होता है, फिर वह समस्त प्राणियों एवं वनस्पतियों में एक ही परमात्मा का दर्शन करता है। ऐसा व्यक्ति सबके हित तथा कल्याण की कामना करता है, वह किसी का शोषण या दोहन नहीं करता। ऋषियों ने इसे ही आस्तिकता पूर्ण आध्यात्मिक जीवन दृष्टि कहा है (आचार्य, 1972)। आस्तिकता का संर्वधन वर्तमान विभीषिकाओं के समाधान का सरल उपाय है।

\section{वृक्षारोपण}

वृक्ष परोपकार के प्रतीक हैं, जो बिना कुछ मांगे पशु-पक्षियों तथा मनुष्य को प्राणवायु, फल, ईंधन तथा अन्य जीवनोपयोगी चीजें प्रदान करते हैं। वृक्ष वर्षा तथा प्रदूषण नियंत्रण के साथ-साथ पारिस्थतिकी संतुलन में महत्त्वपूर्ण योगदान देते हैं। अथर्ववेद में पर्यावरणीय सुरक्षा एवं औषधीय गुणों के कारण वृक्षों की तुलना परोपकारी पुरुष से की गयी है (अथर्ववेद $-8 / 7 / 10) \mid$ भगवान श्रीकृष्ण ने श्रीमद्भगवद् गीता (श्रीमद्भागवत गीता- $10 / 25$ ) में स्वयं को वृक्षों में पीपल बताकर उनके महत्त्व को उजागर किया है। ऋग्वेद में कहा गया है कि वृक्षो से आच्छादित पर्वत प्रदूषण को कम करते हैं (ऋग्वेद $-8 / 7 / 5)$ । मैत्रायणी संहिता में वनस्पवियों को वायुरक्षक कहा गया है (मैत्रायणी संहिता $3 / 9$ 4)। शतपथ ब्राह्मण में वनस्पतियों को प्रदूषकों को अवशोषित करने वाला कहा गया है (शतपथ ब्राह्मण $2 / 2 / 4 / 5)$ । मत्सय पुराण में दस पुत्रों के बराबर एक वृक्ष को माना गया है (मत्स्य पुराण - 10/113)।

पर्यावरण को शुद्ध रखने के लिए मनुस्मृति में गाँव की सीमाओं तथा अन्य स्थलों पर ग्रामपालों को पीपल, किंशुक, ताड़, साल, सेमल, तथा अन्य बड़े वृक्षों को लगवाने का आदेश दिया गया है। इनसे पर्यावरण की शुद्धता बनी रहती है और साथ ही भू-क्षरण भी रुकता है (मनुस्मृति 8/247-48)। यदि बालूदार भूमि हो तो उसमें झाड़ियाँ, बाँस के झुरमुट, शमी-लताओं, शरों और अपामार्ग भी लगायी जाती है। वृक्ष परोपकार के प्रतीक हैं इसलिए ऋषियों ने श्रावणी पर्व के साथ वृक्षारोपण जैसा पुनीत कार्य जोड़ दिया। ऋग्वेद में कहा गया है कि जिस प्रकार बाज पक्षी दूसरे पक्षियों को दु:ख देता है और मार डालता है, तुम वैसे न बनों, इन वृक्षों को दुःख न दो क्योंकि ये पशु-पक्षियों को शरण देते हैं (ऋग्वेद - 6/48/17)। अथर्ववेद (अथर्ववेद - $12 / 1 / 57)$ में तो कठोर शब्दों में कहा गया है कि जो वृक्ष-वनस्पतियों को नष्ट कर पृथ्वी को सताता है, उन्हें धरती मॉ स्वयं पीड़ित कर देती हैं। इस प्रकार भारतीय
संस्कृति में वृक्षों के महत्त्व को समझते हुए उनके संवर्धन एवं संरक्षण पर विशेष बल दिया गया है।

\section{अहिंसा}

भारतीय संस्कृति में अहिंसा को प्रमुख धर्म (अहिंसा परमो धर्म:) मानते हुए कहा गया है 'मा हिंस्याति सर्वभूतानि' अर्थात किसी भी प्राणी की हिंसा मत करो। हिंसा की बात तो दूर भारतीय संस्कृति में उनकी निन्दा करना भी पाप माना गया है (छांदोग्योपनिषद $-1 / 10$ )। इस संस्कृति में विविध पशुओं के रूप में मत्स्य, कच्छप, कूर्म, वराह, नृसिंह आदि अवतारों का उल्लेख मिलता है जो मनुष्यों में पशुओं के प्रति आदर व सम्मान का भाव जागृत करता है। इसके अलावा श्रीमद्भगवद् गीता में भगवान श्रीकृष्ण ने कहा है कि मैं वृक्षों में पीपल, अश्वों मे उच्चै:श्रवा, गजों में ऐरावत, गायों में कामधेनु, सर्पों में वासुकि, पशुओं में सिंह तथा पक्षियों में विष्णु वाहन गरुण हूँ (श्रीमद्भागवत गीता - 10/26-30)। यज्ञों के लिए यूप हेतु हरे वृक्ष को प्रार्थना करके काटा जाता था। इसके अलावा अन्य उपयोग के लिए हरे वृक्ष को काटना पाप माना जाता था। याज्ञिक यूप के लिए जब लकड़ी काटता था तब वह वृक्ष से प्रार्थना करता था कि 'हे वृक्ष! यज्ञ के लिए मैं तुम्हारा वरण करता हूँ इसलिए तुम्हें काट रहा हूँ। मेरी रक्षा करना, मुझे पीड़ा मत पहुँचाना। तुम सौ-सौ अंकुरों से नहीं, सहस्त्र अंकुरों के साथ पुनः हरे-भरे होकर बढ़ना (वाजसनेयी संहिता - $5 / 42-43$ )। अर्थर्वेद में भूमि से प्रार्थना करते हुए ऋषि कहता है कि हे माँ ! मैं तेरे वृक्षों को काटूँ तो वे शीघ्र ही मुकुलित हो जावें, मैं उन्हें पूर्णतः काटकर तेरे मर्म पर चोट न कर बैठूँ (अथर्ववेद $12 / 2 / 35)$ ।

भारतीय संस्कृति में पशु-पक्षियों एवं वृक्ष-वनस्पतियों के प्रति अहिंसा एवं कृतज्ञता के भाव के पीछे पर्यावरण के प्रति गहन जागरूकता का संदेश छिपा 
गये हैं उनमें स्वच्छता का भी स्थान है (महाभारत -शांतिपर्व $60 / 8$ )। ऋग्वेद में कहा गया है कि अंतरिक्ष में कल्याणकारी हवा चलती है और हवा एक स्थान पर बंद न होकर स्वच्छन्द रूप से सर्वत्र प्रवाहित होती रहे (ऋग्वेद $6 / 12 / 13)$ । समस्त धार्मिक कृत्यों एवं अनुष्ठानों में जल के प्रयोग के कारण भारतीय संस्कृति में जल की स्वच्छता एवं पवित्रता का विशेष महत्त्व है। जल को देवता के रूप में प्रतिष्ठित कर ऋषियों ने उनसे प्रार्थना की है कि हे आपो देवता! आप हमें स्वास्थ्य एवं शांति प्रदान करें, नदियों एवं जलाशयों का जल मधुर हो, साथ ही सभी को रोगमुक्त करने वाला जल उपलब्ध हो (अथर्ववेद - 19/2/1-2)। प्राचीन समय में जल दूषित न हो इसका बड़ा ध्यान रखा जाता था, क्योंकि स्नान, तर्पण, आचमन आदि समस्त शुद्धि 
प्रत्येक घटक को देवतुल्य मानकर संरक्षित एवं विकसित करने का प्रयास-पुरूषार्थ अपनाना होगा।

मनोज कुमार राव, पी-एच.डी., प्रवक्ता, भारतीय इतिहास एवं संस्कृति विभाग, देव संस्कृति विश्वविद्यालय, हरिद्धार, भारत।

\section{संदर्भ सूची}

आचार्य, श्रीराम शर्मा (1972). अध्यात्मवाद ही क्यों ? मथुरा, भारत : अखड ज्योति संस्थान, (पृ. 29)। 